\title{
Prevalence of COPD and tobacco smoking in Malopolska region - results from the BOLD Study in Poland
}

\author{
Częstość występowania POChP i rozpowszechnienie palenia tytoniu w Małopolsce - wyniki \\ badania BOLD w Polsce
}

\author{
Ewa Nizankowska-Mogilnicka', Filip Mejza' ${ }^{1}$ A. Sonia Buist ${ }^{2}$, William M. Vollmer ${ }^{3}$, Wojciech Skucha ${ }^{4}$, \\ Rafal Harat ${ }^{5}$, Andrzej Pajak ${ }^{6}$, Jerzy Gasowski , Jakub Frey ${ }^{5}$, Pawel Nastalek', Magdalena Twardowska ${ }^{8}$, \\ Joanna Janicka ${ }^{4}$, Andrzej Szczeklik ${ }^{8}$. \\ ${ }^{1}$ Division of Pulmonary Diseases, Department of Internal Medicine, Jagiellonian University School of Medicine, Krakow, Poland \\ 2 Oregon Health and Sciences University, Portland, OR, USA \\ ${ }^{3}$ Kaiser Permanente Center for Health Research, Portland, OR, USA \\ ${ }^{4}$ District Hospital Proszowice, Pulmonary Diseases Ward, Proszowice, Poland \\ ${ }^{5}$ District Hospital Chrzanow, Pulmonary Diseases Ward, Chrzanow, Poland \\ ${ }^{6}$ Department of Epidemiology and Population Studies, Health Sciences Faculty, Jagiellonian University School of Medicine, Krakow, Poland \\ ${ }^{7}$ Department of Internal Medicine and Geriatrics, Jagiellonian University School of Medicine, Krakow, Poland \\ ${ }^{8}$ Department of Internal Medicine, Jagiellonian University School of Medicine, Krakow, Poland
}

\begin{abstract}
Introduction. There is a paucity of population-based data on chronic obstructive pulmonary disease (COPD) prevalence in Poland. To address this problem we participated in the Burden of Obstructive Lung Disease (BOLD) Initiative which was developed to provide standardized methods for estimating the prevalence of COPD and its risk factors. Objectives. The study aimed to assess the prevalence of COPD and some of its risk factors in adults aged 40 years and older in the Malopolska region in southern Poland. Patients and methods. Region-representative sample was drawn, basing on the current census data. Detailed BOLD questionnaires as well as pre- and post-bronchodilatator spirometry were applied to eligible individuals. Results. Six hundred and three subjects provided questionnaire and spirometry data; of those 526 provided spirometry data of appropriate quality and were included in the final analysis. Estimated population prevalence of COPD was $22.1 \%$, whereas $10.9 \%$ had COPD in GOLD Stage $\geq 2$. COPD was far more common in men and its prevalence increased with age and exposure to tobacco smoke, and was inversely related to education level. The prevalence of current tobacco smoking was $28 \%$ ( $34 \%$ and $22 \%$ in men and women, respectively). Seventy-nine percent of men and $42 \%$ of women were ever-smokers. Twenty-nine percent of never smoking individuals were passively exposed to tobacco smoke in their households. Conclusions. Our results confirm the high prevalence of COPD in the studied region of Poland and emphasize the need to increase efforts to improve COPD awareness and limit tobacco smoking habit.
\end{abstract}

Key words: COPD, education level, Poland, smoking, prevalence, the BOLD Study

Correspondence to:

Professor Ewa Niżankowska-Mogilnicka, MD, PhD, Klinika Pulmonologii II Katedry Chorób Wewnętrznych, Collegium Medicum Uniwersytetu Jagiellońskiego, Skawińska 8, 31-066 Kraków, Poland, phone/fax: +48-12-430-51-58, e-mail: ewa.nizankowska@ mp.pl

Received: October 31, 2007. Accepted in final form: November 7, 2007.

Conflict of interest: none declared.

Pol Arch Med Wewn. 2007; 117 (9): 402-409

Copyright by Medycyna Praktyczna, Kraków 2007

\section{INTRODUCTION}

The prevalence of chronic obstructive pulmonary disease (COPD) in Europe is estimated to be as high as $4-10 \%$ of the adult population [1,2]. The disease has a detrimental impact on quality and length of life of affected individuals, as well as on population health status. It is estimated to be the 5th leading cause of mortality worldwide, and is projected to rank 3rd by 2020 [3]. Chronic obstructive pulmonary disease also results in noticeable consumption of health 
care resources [4]. As a consequence, COPD causes a large, though not yet precisely estimated, economic burden [5]. Despite its paramount medical, social and economic consequences, public awareness of COPD is alarmingly low [3]. A substantial percentage of COPD patients either do not receive proper medical diagnosis or are not diagnosed until the late stages of the disease [6].

Only a few studies have assessed the prevalence of COPD in Poland [7-9], and the estimates varied widely, ranging from $8.5 \%$ in men and 4.9 in women [7] up to $10.7 \%$ in both sexes in an urban adult population [8,9]. A limitation of the Polish and international literature on COPD is that comparison of prevalence estimates is limited by variation in: the definitions of COPD used, the populations studied, and sampling methodologies used [7-10]. In particular, prevalence assessments can be based on self-reported medical diagnosis, spirometry and/or questionnaires. The Global Obstructive Lung Disease (GOLD) Initiative has helped to alleviate this problem through its proposed and widely adopted system for the definition and classification of COPD [3]. More recently the Burden of Obstructive Lung Disease (BOLD) study was started in an attempt to provide a standardized framework for estimating (using the GOLD criteria) the prevalence of COPD and its risk factors, along with an estimate of the economic burden of COPD, in different countries around the world [11].

In this paper we report on the implementation of the BOLD protocol in a population-based sample of residents of the Malopolska region in southern part of Poland. We present data on the prevalence of COPD and selected risk factors (particularly smoking) in this population. This report expands on data recently presented as part of an international comparison of COPD prevalence among participating twelve BOLD sites [12].

\section{PATIENTS AND METHODS}

The study was performed using the BOLD methodology as briefly described below. Further details about the design and rationale of BOLD and its primary results are available elsewhere [11,12].

\section{Participants}

The target population (172,667 individuals) consisted of residents of the two districts (Chrzanow and Proszowice) of the Malopolska region in southern Poland. Using information from current census data, we conducted an age-gender stratified random sample of 800 adults aged 40 years and older in an attempt to recruit 600 study participants. Institutionalized individuals were excluded, as were those precluded from lung function testing for safety reasons.

\section{Examinations}

Study measurements consisted of a series of questionnaires and objective measurement of lung function (spirometry). The questionnaire data included information about respiratory symptoms, activity limitation, diagnosed airways diseases, tobacco smoke exposure, health status, use of biomass fuels for cooking or heating, and occupational exposures.

Spirometry was performed according to American Thoracic Society (ATS) guidelines [13] using ATS-certified, portable, battery operated, ultrasound-based spirometer EasyOne $^{\mathrm{TM}}$; ndd Medical Technologies, Chelmsford MA, USA, and Zurich, Switzerland). The procedure, which was performed with participants in the seated position and wearing nose clips, was done before and at least 15 minutes after administration of $400 \mathrm{mcg}$ of a bronchodilator (salbutamol) via metered-dose inhaler with a spacer (Volumatic; GlaxoSmith-Kline; Research Triangle Park, NC). Spirometers were calibrated on each study day using a 3.00-liter syringe. If the quality of spirometry (as accessed automatically by the spirometer) had not been satisfactory, the maneuver was repeated until the technician judged that the best quality for a given subject was obtained (up to 10 times). During the study, spirometry data were periodically transferred to the Pulmonary Function Reading Center (Salt Lake City, UT, USA) where they were individually reviewed and graded; only spirometries fulfilling ATS quality criteria [13] were included into analysis. Height was measured using portable stadiometers.

Study technicians were trained and certified at the outset of the study and their work was carefully supervised during the study. Those who failed to produce acceptable quality results were temporarily removed from the study until re-trained and re-certified. Interviews and examinations were performed either in local field centers or in participants' houses as needed.

Summary spirometry measures reported here include the one-second forced expiratory volume $\left(\mathrm{FEV}_{1}\right)$, the forced vital capacity (FVC), and their ratio $\mathrm{FEV}_{1} / \mathrm{FVC}$. Both $\mathrm{FEV}_{1}$ and FVC were measured as the maximum value from among acceptable maneuvers, while $\mathrm{FEV}_{1} / \mathrm{FVC}$ was defined as the simple ratio of these two measures.

\section{Definitions}

COPD and its stages were defined according to GOLD guidelines. All stages refer to post-bronchodilator values: Stage 1: $\mathrm{FEV}_{1} / \mathrm{FVC}<0.7$ and $\mathrm{FEV}_{1} \geq 80 \%$ predicted; Stage 2: $\mathrm{FEV}_{1} / \mathrm{FVC}<0.7, \mathrm{FEV}_{1} \geq 50$ and $<80 \%$ predicted; Stage 3: $\mathrm{FEV}_{1} / \mathrm{FVC}<0.7$ and $\mathrm{FEV}_{1} \geq 30$ and $<50 \%$; Stage $4: \mathrm{FEV}_{1} /$ FVC $<0.7$ and $\mathrm{FEV}_{1}<30 \%$ predicted [3]. The third United States National Health and Nutrition Examination Study (NHANES III) reference values for Caucasian men and women $[14]$ were used to obtain predicted lung function measurements (BOLD uses a common set of prediction equations to facilitate cross-site comparisons). Education level data were based on self-reported years of education and classified accord- 
ing to education system in Poland as low ( $\geq 8$ years), middle (9-12 years) and high ( $>12$ years).

\section{Statistical analysis}

We used SAS software package (SAS Institute, Cary, NC), version 9.1, for database management and statistical analysis. We compared means and proportions by standard normal z-test and the $\chi^{2}$ statistic, respectively. SAS PROC SURVEYMEANS procedure was used to derive suitably weighted estimates (and standard errors) of continuous traits and proportions for the combined populations of Chrzanow and Proszowice as a whole. For binary response variables in order to check for the linearity of relations, with or without adjustment for possible confounders, we used logistic regression as supplied in PROC LOGISTICS procedure with appropriate weighting. In the sensitivity analyses, we additionally adjusted the loglinear models for the area of recruitment.

\section{Ethical issues}

The study was approved by the Bioethics Committee of the Jagiellonian University Medical School, Krakow. All participants gave written, informed consent.

\section{RESULTS}

Among the 762 individuals whom we ultimately attempted to recruit for the study, 603 (79.1\%) provided questionnaire and post-bronchodilator spirometry, and of this latter group $526(87.2 \%)$ had acceptable quality spirometry data and were included in this analysis. Compared to nonresponders, those agreeing to participate in the study were significantly older and more likely to have ever smoked. In addition, those with acceptable quality spirometry were significantly younger than responders without acceptable quality spirometry.

The study sample consisted of 266 men and 260 women. The mean $( \pm S D)$ age of the cohort was $55.7 \pm 11.5$ years and did not differ significantly between men and women (Tab. 1).
Table 1. Characteristics of the studied population (unweighted data for study sample)

\begin{tabular}{|c|c|c|c|c|}
\hline & Total & Men & Women & p value ${ }^{*}$ \\
\hline $\mathbf{n}$ & 603 & 303 & 300 & \\
\hline \multicolumn{5}{|l|}{ Age, years (\%) } \\
\hline $40-49$ & 37.5 & 38.0 & 39.9 & \multirow{4}{*}{0.67} \\
\hline $50-59$ & 27.4 & 28.2 & 26.5 & \\
\hline $60-69$ & 20.3 & 19.5 & 21.2 & \\
\hline$\geq 70$ & 14.8 & 14.3 & 15.4 & \\
\hline \multicolumn{5}{|c|}{ Smoking status (\%) } \\
\hline current smokers & 29.1 & 36.1 & 21.9 & \multirow{3}{*}{$<0.001$} \\
\hline former smokers & 32.3 & 42.9 & 21.5 & \\
\hline never smokers & 38.6 & 21.0 & 56.5 & \\
\hline \multicolumn{5}{|c|}{ Education, years (\%) } \\
\hline$\leq 8$ & 34.8 & 30.8 & 38.9 & \multirow{3}{*}{0.13} \\
\hline $9-12$ & 40.9 & 43.6 & 38.0 & \\
\hline$>12$ & 24.3 & 25.6 & 23.1 & \\
\hline * 2-sided $p$ values & test & & & \\
\hline
\end{tabular}

Mean years of education (10.5 \pm 3.4 years) also was similar for men and women. However, a history of current or past smoking was significantly greater in men than women $(78.9 \%$ vs. $42.1 \%$, $\mathrm{p}<0.0001)$. Despite the differences in smoking history between men and women, percent of predicted $\mathrm{FEV}_{1}$ and FVC did not differ between sexes (Tab. 2). However, $\mathrm{FEV}_{1} / \mathrm{FVC}$ was slightly, though significantly, higher in women.

Sixty percent of the combined population of Chrzanow and Proszowice aged 40 and older are estimated to be ever-smokers, while the prevalence of current smoking in this population is estimated to be $28 \%$. Smoking was more prevalent in men than in women (especially among older individuals) (Fig. 1).

Current smoking was common at all education levels, yet tended to be slightly higher in middle educated individuals. However, no statistically significant trend of change in smoking habit with changing education level was found, either in the entire population, or in men and women separately (Fig. 2).

Table 2. Lung function by sex (weighted population estimates)

\begin{tabular}{lcccc}
\hline Post-bronchodilatator values & Total & Men & Women & Weighted p* \\
\hline FEV $_{1}$ (L) & $2.9(1.0)$ & $3.3(0.9)$ & $2.4(0.7)$ & $<0.0001$ \\
\hline FEV 1 (\%, predicted) & $94.8(20.1)$ & $94.5(20.4)$ & $95.0(19.8)$ & 0.72 \\
\hline FVC (L) & $3.8(1.1)$ & $4.5(1.0)$ & $3.1(0.8)$ & $<0.0001$ \\
\hline FVC (\%, predicted) & $97.7(18.5)$ & $97.8(16.7)$ & $97.6(20.3)$ & 0.88 \\
\hline FEV $/$ FVC (\%) & $75.1(9.3)$ & $73.9(10.0)$ & $76.2(8.3)$ & 0.005 \\
\hline
\end{tabular}

* 2-sided $\mathrm{p}$ values based on z-tests for comparing population-based estimates

Data expressed as mean (SD). Abbreviations: $\mathrm{FEV}_{1}$ - one-second forced expiratory volume, FVC - forced vital capacity 


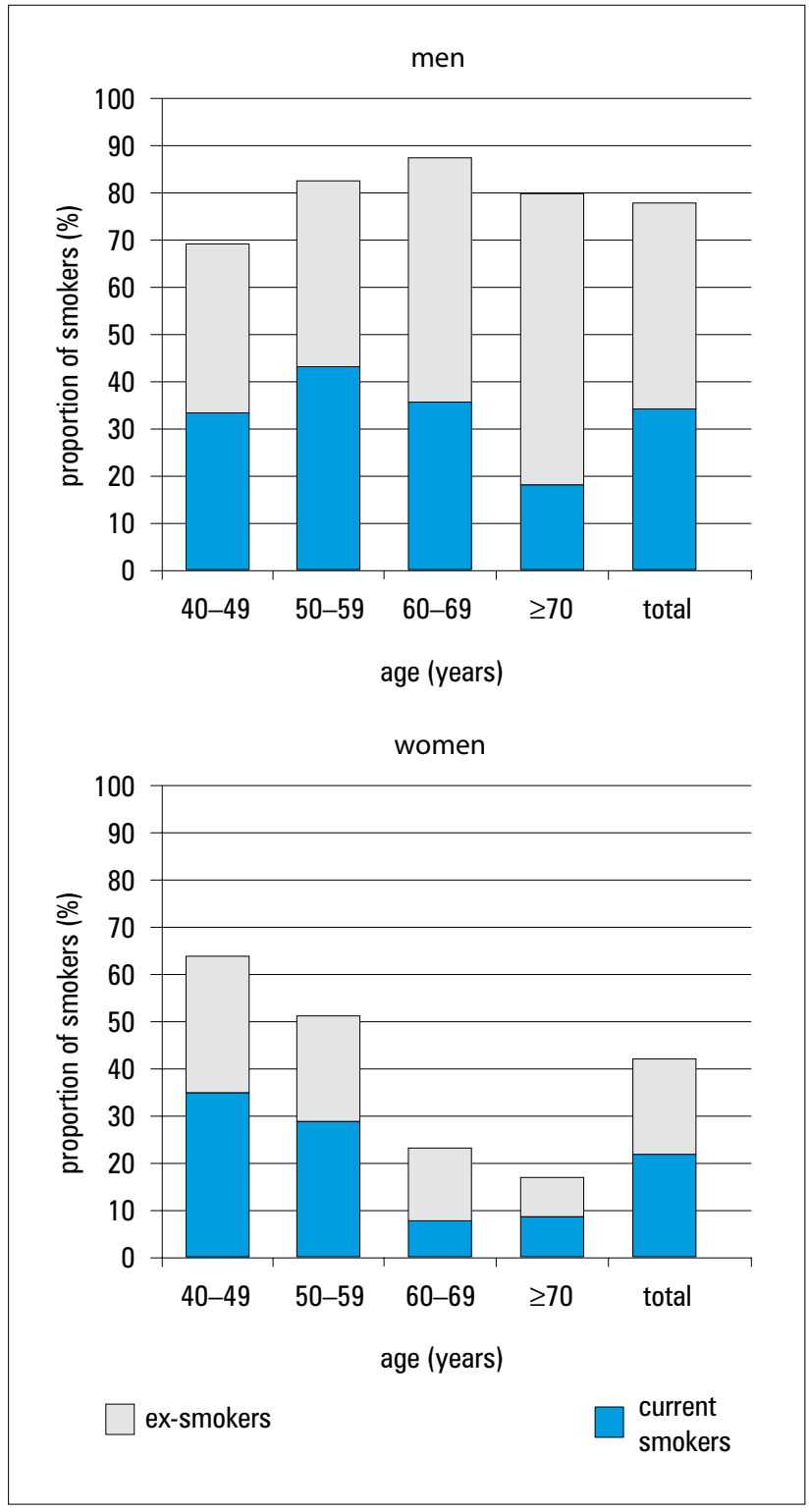

Fig. 1. Proportion of smokers and ex-smokers by sex and age (weighted population estimates)

Ever-smoking subjects have smoked on average 24.3 pack-years (SD 20.4). Men smoked significantly more than women (respectively 29.2 vs. 15.1 pack-years, p <0.0001) (Fig. 3).

$29.3 \%$ of never-smokers, $30.1 \%$ of women and $26.8 \%$ of men were exposed to tobacco smoke in their households during the last 2 weeks before the survey was performed. Other environmental risk factors will be reported separately.

The estimated prevalence of COPD (GOLD Stages $\geq 1$ ) in Malopolska region was $22.1 \%$, while the prevalence of GOLD Stages $\geq 2$ COPD was $10.9 \%$. Almost half of individuals aged 70 years and older (including three-quarters of men in this age group) are estimated to meet GOLD criteria for COPD. Chronic obstructive pulmonary disease prevalence

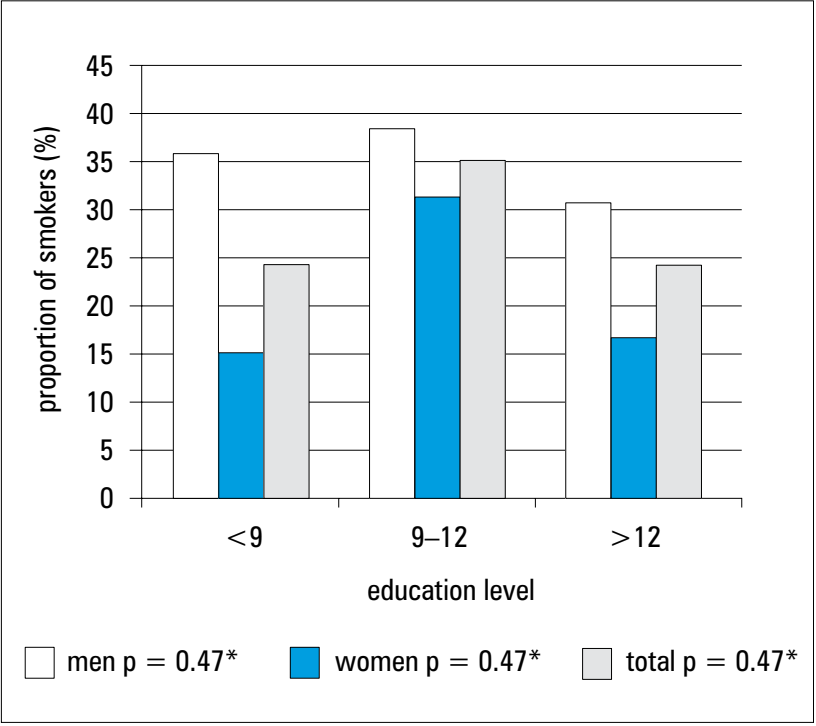

Fig. 2. Proportion of current smokers by education level and sex (* weighted $\mathrm{p}$ for trend in education groups)

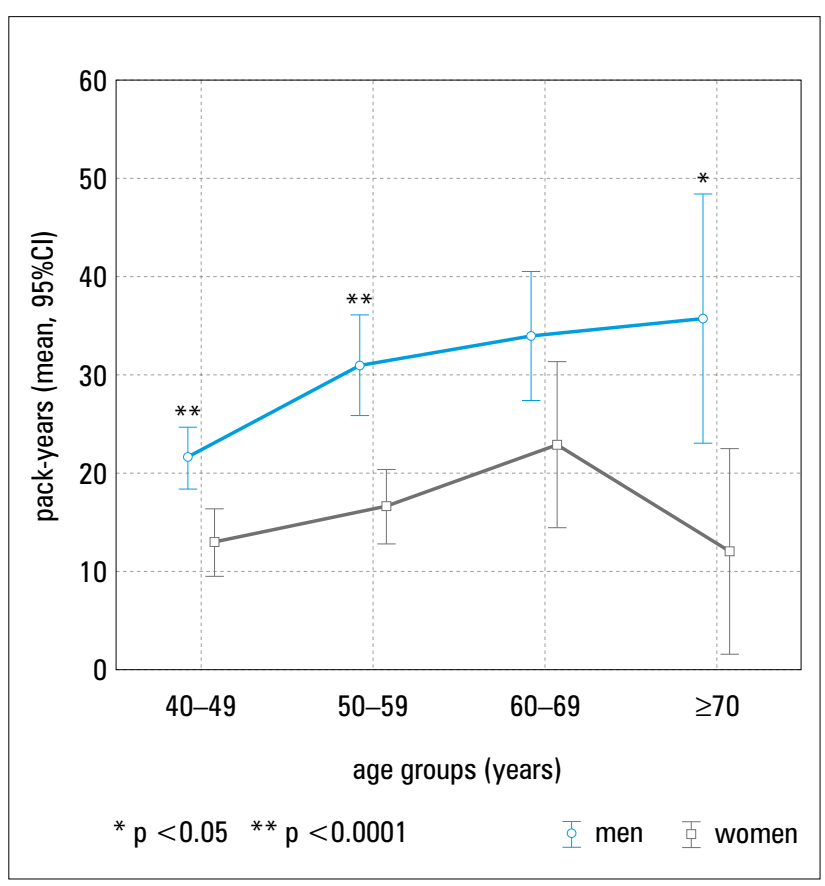

Fig. 3. Pack-years of smoking by age and sex (weighted population estimates)

increased with age in both sexes, and for each age group was greater in men than in women (Tab. 3 and 4).

Only 10 individuals met criteria for GOLD Stages 3 or 4 COPD, with an estimated population prevalence of $1.9 \%$ (SE 0.6) (3.0\% [SE 1.0] in men and 0.8\% [SE 0.6] in women).

Prevalence of COPD (GOLD Stage $\geq 1$ ) and COPD in stage $\geq 2$ also increased with increasing pack-years of cigarette smoking in men (Fig. 4 and 5). The number of ever-smoking 
ARTYKUŁY ORYGINALNE

Table 3. Estimated population prevalence of GOLD Stage $\geq 1$ and higher by age and sex

\begin{tabular}{lllllll}
\hline Age (years) & $\mathbf{4 0 - 4 9}$ & $\mathbf{5 0 - 5 9}$ & $\mathbf{6 0 - 6 9}$ & $\geq \mathbf{7 0}$ & Total & p for trend \\
\hline Men & $8.0(2.9)$ & $22.5(4.8)$ & $40.2(7.0)$ & $74.2(7.5)$ & $27.7(2.4)$ & $<0.0001$ \\
\hline Women & $3.0(1.7)$ & $10.7(3.8)$ & $32.1(5.5)$ & $31.2(7.1)$ & $16.6(2.1)$ & $<0.0001$ \\
\hline Total & $5.7(1.7)$ & $16.8(3.1)$ & $35.9(4.4)$ & $49.6(5.2)$ & $22.1(1.6)$ & $<0.0001$ \\
\hline
\end{tabular}

Standard errors shown in parentheses

\begin{tabular}{|c|c|c|c|c|c|c|}
\hline Age (years) & $40-49$ & 50-59 & $60-69$ & $\geq 70$ & Total & p for trend \\
\hline Men & $2.1(1.5)$ & $10.4(3.4)$ & $19.9(5.5)$ & $40.4(8.2)$ & $13.3(1.9)$ & $<0.0001$ \\
\hline Women & $2.0(1.4)$ & $6.1(2.9)$ & $15.3(4.4)$ & $15.8(5.3)$ & $8.6(1.7)$ & 0.0005 \\
\hline Total & $2.1(1.0)$ & $8.3(2.3)$ & $17.5(3.5)$ & $26.3(4.7)$ & $10.9(1.3)$ & $<0.0001$ \\
\hline
\end{tabular}

Standard errors shown in parentheses

women with COPD ( $\mathrm{n}=12)$ made estimations done in women unreliable.

Prevalence of COPD (GOLD Stage $\geq 1$ ) and COPD in Stage $\geq 2$ decreased with education level (Fig. 6).

In our population, after adjustment for sex, age, and smoking anytime in the lifetime, education higher by one level was associated with 35\% (95\% CI, 10-63, p = 0.009) lower probability of diagnosing COPD GOLD Stage $\geq 1$, and $35 \%$ (95\% CI, $1-68, \mathrm{p}=0.05$ ) lower probability of diagnosing COPD GOLD Stage $\geq 2$.

In sensitivity analyses, additional adjustment for region of population recruitment did not alter the results.

\section{DISCUSSION}

Prevalence of COPD in the studied region of southern Poland was found to be very high. Prevalence of all COPD i.e. GOLD Stage 1 and higher was $22.1 \%$ (27.7\% in men and $16.6 \%$ in women), and COPD in GOLD Stage 2 and higher constituted about half of these cases (11.9\% overall; $13.3 \%$ in men and $8.6 \%$ in women). GOLD Stage 2 and higher COPD is often referred to as "clinically significant" COPD in that these individuals usually have symptoms of the disease and thus need (or will need) medical attention and represent high burden of COPD in the coming years in Poland.

Based on census data $[15]$ it can be extrapolated that there are about 3,800,000 people in Poland with COPD, with almost 2,000,000 suffering from COPD in Stage $\geq 2$. Our results are based on population sample from particular two districts of Poland and thus cannot be regarded as fully representative for the country as a whole. However, cultural uniformity across Poland, similar smoking patterns [16] and the inclusion of participants from both rural and urban areas could partially justify such an approach. Nevertheless, data from simi-

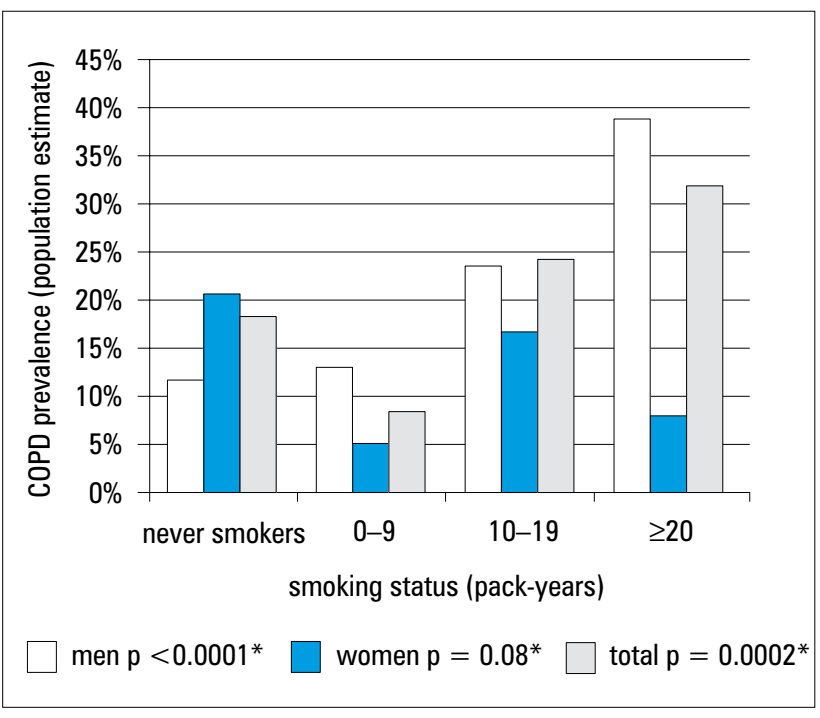

Fig. 4. Prevalence of GOLD Stage 1 and higher by pack-years and sex (weighted population estimates, ${ }^{*} p$ value for trend). COPD chronic obstructive pulmonary disease

lar studies performed in such methodologically stringent way would be welcomed in other regions of Poland.

Results of recently published estimations in adults from 2 big cities in Poland reported COPD prevalence about $10 \%$ [8,9]. In a survey of Warsaw city inhabitants aged 40 years and older, the reported prevalence of COPD (defined as $\mathrm{FEV}_{1} / \mathrm{FVC}<0.7$ and presence of COPD symptoms) was $10.7 \%$ [8]. A second study (using similar criteria to define COPD) found a prevalence of $10.2 \%$ in the city of Zabrze among subjects older than 18 years [9]. However, both of these studies presented sample data rather than population estimates. An earlier 1981 study of 1864 individuals aged 32 and older reported a prevalence of $8.5 \%$ in men and $4.9 \%$ in women, 
ARTYKUŁY ORYGINALNE

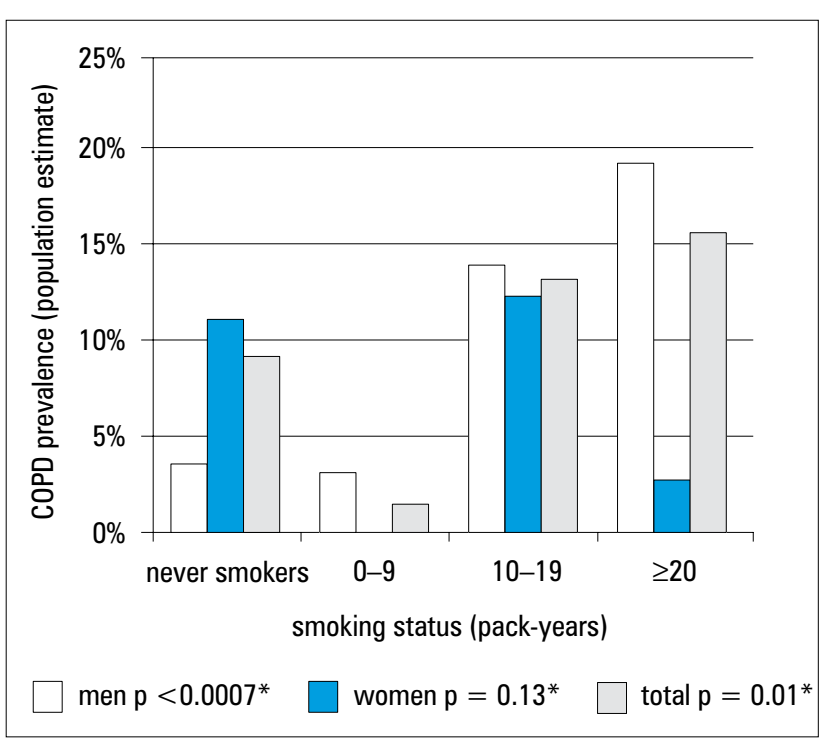

Fig. 5. Prevalence of GOLD Stage 2 and higher by pack-years and sex (weighted population estimates, ${ }^{*} p$ values for trend). Abbreviation - see Figure 4

although this was based on a somewhat more stringent definition of COPD [7]. Despite the fact that our data cannot be directly compared with the above results from previous studies due to differences in methods used, COPD prevalence reported in our study based on region-representative sample in southern Poland is higher than expected. This is a piece of information of paramount importance, taking into account the significant social burden and medical costs of COPD.

Recently published global results of BOLD Study in which Poland also participated, have shown COPD prevalence to be higher than previously estimated in another eleven countries, from Europe, US, Australia and South Africa [12]. Burden of Obstructive Lung Disease Study in Austria has brought quite similar results to those in Poland (estimated population prevalence of COPD in Stage 1 or higher $-26.1 \%$ and in Stage 2 or higher $-10.7 \%$ ) [17]. Total proportion of COPD patients is similar in Austria and Poland, yet important differences exist in sex structure of COPD patients. This finding can be partially explained by the differences in frequency of smoking habit in Poland and Austria (more ever-smoking women in Austria). The results of earlier studies assessing COPD prevalence in Europe are remarkably different, with lower COPD prevalence, ranging from 8 to $14 \%[18,19]$. The study from Greece has estimated the prevalence of COPD to be $8.4 \%$ in smokers older than 35 years old [18], while the OLIN Study carried out in Northern Sweden in the population older than 45 years reported a prevalence of COPD in GOLD Stage $\geq 1$ of $14 \%$ [19]. It should be emphasized, however, that part of the discrepancies between all these studies result from the influence of different COPD definitions on estimated disease prevalence as it was demonstrated in the study based on data from the NHANES III carried out in the USA [20]. Differences in methodology between studies make cross-study compari-

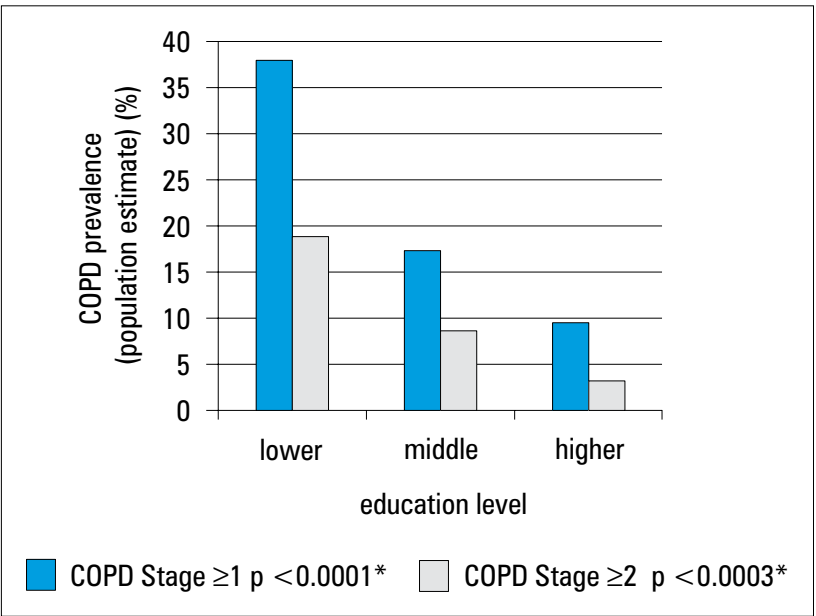

Fig. 6. Prevalence of COPD in GOLD Stage $\geq 1$ and COPD in GOLD Stage $\geq 2$, by education level (weighted population estimates, * $p$ value for trend). Abbreviation - see Figure 4

sons unreliable and underline the importance of epidemiological studies performed according to common, widely accepted methodology, such as BOLD Study.

As expected, COPD prevalence in our study increased steeply with age similar to results found in many other countries using the same BOLD methodology [12] and in many other previous epidemiological studies $[18,19]$. COPD prevalence increased also with smoking. However, the latter relationship was clearly demonstrated in our study only in men. Two factors could have influenced this finding. Firstly, the total burden of tobacco smoke was significantly greater in smoking men than in smoking women in all age groups and it could result in higher COPD prevalence in men. Secondly, the absolute number of smoking women with COPD in our sample was low, making the analysis of this group difficult.

Prevalence of COPD both in Stage $\geq 1$ ( $17.8 \%$ overall) and Stage $\geq 2$ ( $9.2 \%$ overall) in never-smokers, especially in women $(20.1 \%$ in GOLD Stage $\geq 1$ and even $11.2 \%$ in GOLD Stage $\geq 2$ ), was surprisingly high in our country, much higher in comparison to other countries participating in BOLD Study [12], indicating the need to investigate for other COPD risk factors in this group of women. Some of these COPD cases can be explained by the exposure to passive smoking, which was found in about $1 / 3$ of non-smoking women. The possible explanation for high prevalence of COPD in never-smoking women could be also an exposure to other environmental risk factors and a greater susceptibility to harmful effect of tobacco smoke [21].

In our study COPD prevalence showed marked differences across education levels in both sexes; COPD was much more prevalent in individuals with the lowest education level. The educational level in BOLD methodology was used as a surrogate for socio-economic status. Logistic regression model has confirmed education level to be a factor independent from sex, age and smoking status in our sample. Education level was 
shown to be related to COPD prevalence in multiple [22,23] but not all studies [24]. Probable explanation for these differences is that education level actually reflects complex influences of multiple lifestyle-related risk factors.

Estimated population frequency of COPD in Stage $\geq 1$ in our study was very high in subjects aged 70 or more (about $74 \%$ in men and over $31 \%$ in women). Using a post-bronchodilator fixed $\mathrm{FEV}_{1} / \mathrm{FVC}$ ratio of less than 0.7 as a threshold for COPD diagnosis in this age group can probably lead to overestimation of the disease prevalence. A population-based study in individuals over 70 years showed $\mathrm{FEV} / \mathrm{FVC}$ ratio below 0.7 in about $35 \%$ of asymptomatic, non-smoking subjects [25]. Study based on the NHANES III data has shown that up to $20 \%$ of elderly subjects with $\mathrm{FEV}_{1} / \mathrm{FVC}$ above 5 th percentile had $\mathrm{FEV}_{1} / \mathrm{FVC}$ ratio below 0.7 [26]. However, recent study has demonstrated that individuals with $\mathrm{FEV}_{1} / \mathrm{FVC}$ ratio below 0.7 and above 5 th percentile have indeed increased risk of COPD-related death or hospitalization [27]. The latter finding in part justifies using fixed $\mathrm{FEV}_{1} / \mathrm{FVC}$ ratio especially in epidemiological studies (such as BOLD study), because this can help to identify subjects who may need medical attention. On the other hand, in our study over $25 \%$ of subjects aged 70 or more had COPD in Stage $\geq 2$, confirming high disease burden in the elderly population. In 2005 census data people $>60$ years old constituted $17 \%$ of society, but in 2020 this percentage is projected to grow up to $26 \%$ [15]. This changes in age structure of the society alone in Poland will undoubtedly lead to further increase in COPD prevalence.

Reported smoking prevalence rate in our study was almost $28 \%$, which is roughly in concordance with assessment $(31 \%)$ reported in adults by last available government data (Polish National Statistics Office) [28]. Prevalence of ever-smoking in studied population was almost $60 \%$ overall and $78 \%$ in men. Some recent studies indicate that COPD prevalence in smokers may be higher than previously estimated [24] and male smokers in our sample had very large burden of almost 30 pack-years. Moreover, the results from a spirometry-based COPD screening program in Poland performed in smokers older than 40 years have already demonstrated a $30 \%$ frequency of airway obstruction [29]. Similar results were found in a screening program done before 2000 in the Proszowice district of the Malopolska region where part of our study was carried out [30].

Thus, every effort should be placed on smoking cessation programs. The prevalence of continued use of tobacco in Poland is decreasing, however, significant smoking burden in the past will increase even more the effect of aging of Polish population on future COPD occurrence. Unfortunately, positive changes in smoking prevalence were observed recently mainly in men (9\% drop in smoking rate for the last 8 years) while in women smoking rate is almost similar for the last years (ca $1 \%$ decrease) [15]. In our study we have found remarkably higher percentage of smokers in women aged 40-60 years than in older groups. This can lead to a possible further increase in COPD prevalence in women.

The limitation of our study was relatively small sample size, however, this made the study easier to perform and was done according to pre-defined BOLD Study methodology [11]. On the other hand we had very good response rate, which was much higher than in previously reported studies in Poland [7-9].

Results of BOLD Study carried out in Poland confirm the high prevalence of COPD in Malopolska region of Poland and indicate the urgent need for increased efforts to improve COPD awareness in health professionals, health authorities and general public as well to augment the prevention programs in Poland.

\section{ACKNOWLEDGMENTS}

The BOLD has been funded in part by unrestricted educational grants to the operations center from ALTANA, Aventis, AstraZeneca, Boehringer-Ingelheim, Chiesi, GlaxoSmithKline, Merck, Novartis, Pfizer, Schering-Plough, Sepracor, and University of Kentucky.

We thank for funding for the BOLD Krakow site from: GlaxoSmithKline Pharmaceuticals, Polpharma, Ivax Pharma Poland, AstraZeneca Pharma Poland, ZF ALTANA Pharma, Pliva Kraków, Adamed, Novartis Poland, Linde Gaz Polska, Lek Polska, Tarchomińskie Zakłady Farmaceutyczne Polfa, Starostwo Proszowice, Skanska, Zasada, Agencja Mienia Wojskowego w Krakowie, Telekomunikacja Polska, Biernacki, Biogran, Amplus Bucki, Skrzydlewski, Sotwin, and Agroplon.

\section{REFERENCES}

1. European Respiratory Society/ European Lung Foundation. Chronic obstructive pulmonary disease. In: Loddenkemper R, Gibson GJ, Sibille Y, eds. European Lung White Book - the First Comprehensive Survey on Respiratory Health in Europe. Sheffield, ERSJ, 2003: 34-43

2. Halbert RJ, Natoli JL, Gano A, et al. Global burden of COPD: systematic review and meta-analysis. Eur Respir J. 2006; 28: 523-532.

3. GOLD Workshop Report 2006: Global Strategy for Diagnosis, Management, and Prevention of COPD. E-published on November 2006; available at GOLD website: http://www.goldcopd.com (accessed May 10, 2007).

4. Pauwels RA, Rabe KF. Burden and clinical features of chronic obstructive pulmonary disease (COPD). Lancet. 2004; 364: 613-620.

5. Chapman KR, Mannino DM, Soriano JB, et al. Epidemiology and costs of chronic obstructive pulmonary disease. Eur Respir J. 2006; 27: 188-207.

6. Coultas DB, Mapel D, Gagnon RC, Lydick E. The health impact of undiagnosed airflow obstruction in a national sample of United States adults. Am J Respir Crit Care Med. 2001; 164: 372-377.

7. Krzyzanowski M, Jedrychowski W, Wysocki M. Factors associated with the change in ventilatory function and the development of chronic obstructive pulmonary disease in a 13-year follow-up of the Cracow Study. Risk of chronic obstructive pulmonary disease. Am Rev Respir Dis. 1986; 134: 1011-1019.

8. Plywaczewski R, Bednarek M, Jonczak L, Zielinski J. Prevalence of COPD in Warsaw population. Pneumonol Alergol Pol. 2003; 71: 329-335.

9. Niepsuj G, Kozielski J, Niepsuj K, et al. Chronic obstructive pulmonary disease in inhabitants of Zabrze. Wiad Lek. 2002; 55: 354-359

10. Halbert RJ, Isonaka S, George D, Iqbal A. Interpreting COPD prevalence estimates: what is the true burden of disease? Chest. 2003; 123: 1684-1692.

11. Buist AS, Vollmer WM, Sullivan SD, et al. The Burden of Obstructive Lung Disease Initiative (BOLD): rationale and design. COPD. 2005; 2: 277-283.

12. Buist AS, McBurnie MA, Vollmer WM, et al. International variation in the prevalence of COPD (the BOLD Study): a population-based prevalence study. Lancet. 2007; 370: 741-750.

13. Standardization of spirometry, 1994 update. American Thoracic Society. Am J Respir Crit Care Med. 1995; 152: 1107-1136. 
14. Hankinson JL, Odencrantz JR, Fedan KB. Spirometric reference values from a sample of the general US population. Am J Respir Crit Care Med. 1999; 159: 179-187.

15. http://www.stat.gov.pl/gus/45_646_PLK_HTML.htm (assessed 17.10.2007).

16. http://www.stat.gov.pl/gus/45 2657_PLK HTML.htm (assessed 17.10.2007).

17. Schirnhofer L, Lamprecht B, Vollmer WM, et al. COPD prevalence in Salzburg, Austria: results from the Burden of Obstructive Lung Disease (BOLD) Study. Chest. 2007; 131: 29-36.

18. Tzanakis N, Anagnostopoulou U, Filaditaki V, et al. COPD group of the Hellenic Thoracic Society. Prevalence of COPD in Greece. Chest. 2004; 125: 892-900.

19. Lundback B, Lindberg A, Lindstrom $M$, et al; Obstructive Lung Disease in Northern Sweden Studies. Not 15 but 50\% of smokers develop COPD? Report from the Obstructive Lung Disease in Northern Sweden Studies. Respir Med. 2003; 97: 115122.

20. Celli BR, Halbert RJ, Isonaka S, Schau B. Population impact of different definitions of airway obstruction. Eur Respir J. 2003; 22: 268-273.

21. Langhammer $A$, Johnsen $R$, Gulsvik $A$, et al. Sex differences in lung vulnerability to tobacco smoking. Eur Respir J. 2003; 21: 1017-1023.

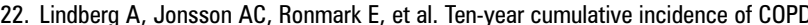
and risk factors for incident disease in a symptomatic cohort. Chest. 2005; 127 1544-1552.

23. Menezes AM, Perez-Padilla R, Jardim JR, et al. PLATINO Team. Chronic obstructive pulmonary disease in five Latin American cities (the PLATINO study): a prevalence study. Lancet. 2005; 366: 1875-1881.

24. Lokke $A$, Lange $P$, Scharling $H$, et al. Developing COPD: a 25 year follow up study of the general population. Thorax. 2006; 61: 935-939

25. Hardie JA, Buist AS, Vollmer WM, et al. Risk of over-diagnosis of COPD in asymptomatic elderly never-smokers. Eur Respir J. 2002; 20: 1117-1122.

26. Hansen JE, Sun XG, Wasserman K. Spirometric criteria for airway obstruction: Use percentage of $\mathrm{FEV}_{1} / \mathrm{FVC}$ ratio below the fifth percentile, not $<70 \%$. Chest. 2007; 131: 349-355.

27. Mannino DM, Buist SA, Vollmer WM. Chronic obstructive pulmonary disease in the older adult: what defines abnormal lung function? Thorax. 2007; 62: 237-241.

28. http://www.stat.gov.pl/gus/45 658 PLK HTML.htm (accessed 17.10.2007).

29. Zielinski J, Bednarek M and the Know the Age of Your Lung Study Group. Early detection of COPD in a high-risk population using spirometric screening. Chest. 2001 119: 731-736.

30. Krawczyk K, Skucha W. Incidence of chronic obstructive pulmonary disease among chronic smokers inhabiting Krakow and Proszowice. Przegl Lek. 2000; 57: 617-618. 